\title{
Verification of performance of a direct fluorescent assay for cell-free DNA quantification, stability according to pre-analytical storage conditions, and the effect of freeze-thawing
}

\author{
JAE-JOON KIM ${ }^{1}$, KWONOH PARK ${ }^{1}$, YU RAN HAN ${ }^{2}$, SY HYUN KIM ${ }^{2}$, SANG-BO OH $^{1}$, \\ SO YEON OH ${ }^{1}$, YUN JEONG HONG ${ }^{3}$ and MI SOOK YUN ${ }^{4}$
}

\author{
${ }^{1}$ Medical Oncology and Hematology, Department of Internal Medicine, Pusan National University Yangsan Hospital, \\ Yangsan-si, Gyeongsangnam-do 50612; ${ }^{2}$ Bionoxx Inc., Seongnam-si, Gyeonggi; \\ ${ }^{3}$ Department of Neurology, Uijeongbu St. Mary's Hospital, Catholic University of Korea, Seoul Special City; \\ ${ }^{4}$ Division of Biostatistics, Research Institute for Convergence of Biomedical Science and Technology, \\ Pusan National University Yangsan Hospital, Yangsan-si, Gyeongsangnam-do 50612, Republic of Korea
}

Received March 30, 2021; Accepted June 7, 2021

DOI: $10.3892 / \mathrm{br} .2021 .1444$

\begin{abstract}
A simple fluorescence-based cell-free DNA (CFD) assay has been previously developed that can directly measure nucleic acids without prior DNA extraction and amplification. However, studies on fluorescence-based CFD are lacking. In particular, there is no known information regarding the stability with regard to pre-analytical storage conditions in relation to time and temperature, or on the influence of freeze-thawing. Plasma was directly assayed to measure CFD using PicoGreen ${ }^{\mathrm{TM}}$ reagent. Standard linearity and accuracy were confirmed using salmon sperm DNA. Whole blood was left at room temperature (RT) and at $4^{\circ} \mathrm{C}$, and then plasma was separated. The CFD was also measured using thawed plasma after 1 week of freezing. As a correlation with a sperm DNA concentration, CFD demonstrated linearity over a wide range of concentrations, with a 0.998 correlation coefficient. The CFD level showed a change of up to $2.5 \mu \mathrm{g} / \mathrm{ml}$ according to pre-analytical storage time, and the changes were not consistent over time. The CFD values at RT after $1 \mathrm{~h}$ were similar to the baseline values, and the relative standard deviation was lowest under this condition. The CFD values between $4^{\circ} \mathrm{C}$ and RT were similar over all time periods assessed. After freeze-thawing, the change in CFD value was reduced compared to that before freezing. The present study showed that CFD measurements using plasma processed within $1 \mathrm{~h}$ were optimal. Additionally, the effects of substantial
\end{abstract}

Correspondence to: Dr Kwonoh Park, Medical Oncology and Hematology, Department of Internal Medicine, Pusan National University Yangsan Hospital, 20 Geumo-ro, Mulgeum-eup, Yangsan-si, Gyeongsangnam-do 50612, Republic of Korea E-mail: parkkoh@daum.net

Key words: cell-free nucleic acids, biomarkers, fluorescence, polymerase chain reaction, freezing changes according to storage conditions were reduced after freeze-thawing, and thus studies using stored samples is viable and relevant.

\section{Introduction}

Cell-free DNA (CFD) can originate from the release of DNA from a cell undergoing apoptosis or necrosis, or from the release of intact cells in the bloodstream and their subsequent lysis (1-4). Several previous studies have reported elevated CFD levels in patients with cancer (2-7). The potential for measuring CFD has been increasingly recognized as a tool for a variety of activities, including diagnosis, monitoring of treatment response and prognosis determination for several different types of cancer $(2,4,8-10)$.

Until recently, quantitative measurement of CFD has been primarily assessed using PCR. However, there are two main problems with PCR. First, it is complex and labor-intensive, particularly with regard to DNA extraction and PCR amplification with specific primers (11). Thus, it is not only inconvenient in terms of cost and time, but also can impede comparison of data between laboratories due to differences in the specifics of the various protocols and differences in the reagents used. Second, there is a lack of clear information on the changes in CFD values according to pre-analytical storage temperature and duration for whole blood before separating the plasma (11). There are other methods for measurement of CFD levels, including droplet digital PCR and the MassARRAY ${ }^{\circledR}$ system (12-14), these methods however, require advanced technology, so may be not easily accessible. CFD values may increase with storage time due to cell lysis (4); conversely, it may be decreased by DNA degradation related to nuclease activity in the blood (15). The stability of CFD values based on storage temperature and time from whole blood sampling to processing by centrifugation is an important issue for application of CFD assays in the hospital. Although there is a general consensus on the value of CFD measurements in a several types of cancer $(3,16)$, CFD assays have been confined to research laboratories. 
A fluorescence-based CFD assay was developed that could directly measure DNA using a simple and inexpensive method without prior DNA extraction and amplification (17). The results of fluorescence-based CFD assays are significantly correlated to the CFD level measured using the PCR method (18), and significant changes in CFD levels according to the efficacy of anticancer treatment has been confirmed $(4,19)$. As standardization of fluorescence-based CFD assays is relatively easy (18), inter-researcher and inter-laboratory differences are expected to be small. However, information on basic performance, including accuracy and reproducibility of fluorescence-based CFD assays is insufficient. In addition, pre-analytical storage conditions prior to plasma processing should be clarified for clinical utility. Finally, even when conducting studies using fluorescence-based CFD assays in a research setting, the assays are generally performed using freeze-thawed plasma specimens. Thus, the effect of freeze-thawing on CFD levels should be determined, to improve confidence in the results. The aim of the present study was to examine the basic performance of fluorescence-based CFD assays as measured by accuracy and stability, and assess the potential effects of pre-analytical storage conditions, and the influence of freezing-thawing.

\section{Materials and methods}

Fluorescence-based CFD assay. Fluorescence-based CFD was directly assayed using Quant-iT PicoGreen ${ }^{\mathrm{TM}}$ dsDNA Reagent (cat. no. P7584; Invitrogen; Thermo Fisher Scientific, Inc.) without DNA extraction or amplification. The CFD in plasma was measured after being diluted with TE buffer (cat. no. V6231; Promega Corporation). All standards and samples were deposited in a $100 \mu \mathrm{l}$ volume in each well of a 96-well microplate. For staining, $100 \mu 1$ PicoGreen reagent was added volume to each sample in black 96-well plates for $3 \mathrm{~min}$ at room temperature $\left(\sim 20^{\circ} \mathrm{C}\right.$; cat. no. SPL30296; SPL Life Sciences Co., Ltd.), and the mixture was diluted 400-fold. Fluorescence intensity was measured with a black 96 -well microplate reader (Spark; Tecan Group, Ltd.) at an emission wavelength of 535 $\mathrm{nm}$ and an excitation wavelength of $485 \mathrm{~nm}$. All assays were performed twice, and the average value was used.

Verification of fluorescence-based CFD. To assess linearity and accuracy, DNA standards were prepared using salmon sperm DNA (10 mg/l; cat. no. 15632-011; Thermo Fisher Scientific, Inc.) that was diluted to $1,000,750,500,250,100$, 10,1 and $0.2 \mathrm{ng} / \mathrm{l}$. A total of 16 independent experiments were performed to analyze the correlation between the mean of the fluorescence intensity and DNA concentration value, and the final measurement range was used after a quantitative standard linearity test to confirm the accuracy at each concentration. To identify an appropriate dilution ratio without interference effects, plasma samples were diluted to 1/2, 1/10, 1/20, 1/50 and 1/100 using TE buffer. Salmon sperm DNA was spiked into the diluted plasma at a concentration of $10 \mathrm{ng} / \mathrm{ml}$ to evaluate the recovery rate for the known amount of DNA.

Stability of CFD according to storage conditions and influence offreeze-thawing. To assess the impact of various storage conditions, whole blood of 5 volunteers were collected for use in the present study. These volunteers did not have acute or chronic disease and were not taking any medication. The group was composed of 2 women and 3 men with a median age of 34 (range, 29-45). A volume of $22 \mathrm{ml}$ peripheral blood drawn from each participant; $2 \mathrm{ml}$ blood was placed in each of the 11 EDTA tubes using a 20 gauge needle. Whole blood samples in each tube were stored at $4^{\circ} \mathrm{C}$ or room temperature for various periods of time $(0,1,2,3,4$ or $6 \mathrm{~h})$ prior to centrifugation. Subsequently, plasma samples were obtained by centrifuging the peripheral blood at 3,000 x $\mathrm{g}$ for $10 \mathrm{~min}$ at room temperature, and the plasma samples were collected as the upper supernatant layer. The CFD value was measured for each condition (temperature and incubation time). The plasma samples obtained for each storage condition were stored in frozen aliquots at $-80^{\circ} \mathrm{C}$ and thawed after a month to assess the potential impact of freeze-thawing and to assess reproducibility. The research protocol was approved by the Institutional Review Board of Pusan National University Yangsan Hospital (Yangsan, Republic of Korea; approval no. 04-2019-024), and written informed consent was obtained from all participants.

Statistics. Standard linearity of fluorescence-based CFD was evaluated using simple linear regression analysis. Relative standard deviation (RSD), which is the standard deviation divided by mean, was used to identify the precision between the averages of the sequentially analyzed results. With regard to analysis of storage conditions and the freeze-thawing effect, the differences in CFD amongst the groups and follow-up periods were compared using repeated measures ANOVA and Bonferroni post hoc tests. Statistical analyses were performed using SPSS version 19.0 (IBM Corp.).

\section{Results}

Basic performance of the fluorescence-based CFD assay. As a result of analyzing the average fluorescence intensity correlation with the sperm DNA concentration, quantification of plasma CFD demonstrated linearity over a wide range of concentrations $(1-1,000 \mathrm{ng} / \mathrm{ml})$ with a strongly positively correlated standard curve $\left(\mathrm{R}^{2}=0.998\right)$ (Fig. 1). The $1 / 50$ diluted plasma showed a $114 \%$ recovery rate at $11.4 \mathrm{ng} / \mathrm{ml}$, whereas the other diluted ratios showed a recovery rate of $\geq 200 \%$, and a notable difference between the spiked DNA concentration. Considering interference effects and recovery, the appropriate dilution ratio was determined to be 1/50 (Table I).

Stability of fluorescence-based CFD according to storage conditions. At both $\mathrm{RT}$ and $4^{\circ} \mathrm{C}$, the $\mathrm{CFD}$ values increased after $1 \mathrm{~h}$, decreased at $2 \mathrm{~h}$, increased after $3 \mathrm{~h}$ and then decreased after $6 \mathrm{~h}$ (Fig. 2). The changes in CFD values were significant according to the time course $(\mathrm{F}=481.038, \mathrm{P}<0.001)$; however, the changes did not show consistency over time. Nevertheless, considering that the CFD values at RT for $1 \mathrm{~h}$ were similar to the baseline CFD values and the RSD values at $1 \mathrm{~h}$ were the most stable. These results suggest that plasma processed from whole blood within $1 \mathrm{~h}$ at RT is optimal. CFD values between $4^{\circ} \mathrm{C}$ and RT were similar over all time periods $(\mathrm{F}=1.004$, $\mathrm{P}=0.346$ ), showing that temperature was not a major factor of storage conditions within $6 \mathrm{~h}$. The mean baseline CFD level was $8.4 \mu \mathrm{g} / \mathrm{ml}$ with a standard deviation of $0.2 \mu \mathrm{g} / \mathrm{ml}$. 
Table I. Interference effect and recovery of fluorescence based cell free-DNA.

\begin{tabular}{|c|c|c|c|c|}
\hline Sample dilution & Spiking, ng/ml & $\mathrm{ng} / \mathrm{ml}$ & Internal control $^{\mathrm{a}}$ & Recovery, \% \\
\hline Sample $1 / 10$ & 0 & 282.8 & - & - \\
\hline Sample $1 / 20$ & 0 & 199.8 & - & - \\
\hline Sample $1 / 50$ & 0 & 123.8 & - & - \\
\hline Sample 1/100 & 0 & 87.2 & - & - \\
\hline Internal control $1 / 10$ & 10 & 264.2 & -18.6 & -185.6 \\
\hline Internal control $1 / 20$ & 10 & 226.4 & 26.6 & 265.7 \\
\hline Internal control $1 / 50$ & 10 & 135.2 & 11.4 & 114 \\
\hline Internal control 1/100 & 10 & 108.9 & 21.7 & 216.8 \\
\hline
\end{tabular}

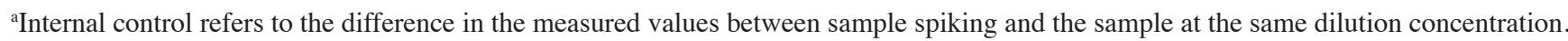

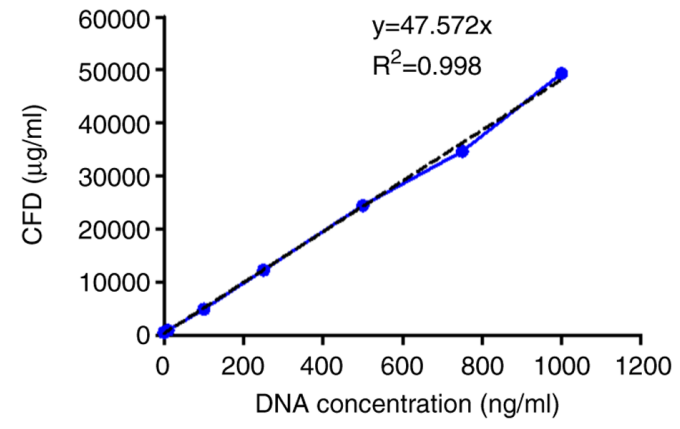

\begin{tabular}{ccccc}
\hline No. & Concentration $(\mathrm{ng} / \mathrm{ml})$ & Average & RSD $(\%)$ & Accuracy $(\%)$ \\
\hline 1 & 0 & 521.4 & 12.0 & \\
2 & 0.2 & 481.0 & 1.9 & \\
3 & 1 & 566.4 & 11.8 & 93.2 \\
4 & 10 & 893.1 & 19.1 & 77.0 \\
5 & 100 & 4858.9 & 16.6 & 89.8 \\
6 & 250 & 12236.1 & 13.8 & 97.0 \\
7 & 500 & 24402.0 & 12.7 & 98.9 \\
8 & 750 & 34613.4 & 10.7 & 94.1 \\
9 & 1000 & 49323.6 & 6.9 & 101.1 \\
\hline
\end{tabular}

Figure 1. Correlation between the direct fluorescent assay and PCR method for measurement of CFD. As a result of analyzing the average fluorescence intensity correlation with the sperm DNA concentration, quantification of plasma CFD demonstrated linearity over a wide range of concentrations $(1-1,000 \mathrm{ng} / \mathrm{ml})$ with a correlating standard curve $\left(\mathrm{R}^{2}=0.998\right)$. RSD, relative standard deviation; CFD, cell free DNA.

Influence of freeze-thawing on the fluorescence-based CFD assay. Plasma samples were stored as aliquots at $-80^{\circ} \mathrm{C}$ and thawed after 1 month to assess the influence of freeze-thawing and reproducibility. There was a significant difference in CFD values after freeze-thawing with regard to storage time ( $F=3.387, P=0.007$; Fig. 3); however, the changes in CFD values were reduced compared to those before freezing (fresh sample, $\mathrm{F}=481.038$; samples after freezing, $\mathrm{F}=3.387$ ). There was no significant difference in CFD values after freeze-thawing with regard to the previously exposed temperature $(\mathrm{F}=1.342$; $\mathrm{P}=0.280$ ).

\section{Discussion}

The present study showed the basic performance of a simple fluorescence-based CFD assay as an accurate method for measuring CFD. Whilst, CFD values exhibited large variability over all time periods depending on storage time during the pre-analytical phase. If processing of blood was not consistently performed at the same time, the CFD values were not reliable. Thus, strict management of pre-analytical storage conditions based on predefined guidelines is necessary. The present study showed that CFD values measured in plasma samples processed within $1 \mathrm{~h}$ at RT were similar to the baseline values, and the RSD was lowest. Hence, pre-analytical conditions of $1 \mathrm{~h}$ at RT were deemed to be optimal for fluorescence-based CFD assays. On the other hand, CFD values were consistent regardless of pre-analytical storage conditions after freeze-thawing, indicating the reliability of results of the fluorescence-based CFD assay using stored plasma, such as that from biobanks.

The fluorescence-based CFD assay using PicoGreen ${ }^{\mathrm{TM}}$ is a convenient and cost-effective method for direct assay of CFD. This method is free from technical issues such as DNA extraction, so there are fewer issues, such as inter-tester-laboratory variations due to the test itself. The PCR assay is expensive and difficult to standardize due to the relative complexity of the methods, exhibiting low reliability due to large variability depending on time of testing and tester (11).

Although the fluorescence-based CFD assay can reduce technical issues, a clear standard for the pre-analytical phase has to be defined. As mentioned above, the present study showed that it is necessary to measure CFD with whole blood processing within $1 \mathrm{~h}$. Prior studies showed that plasma must be separated from whole blood samples within a certain period of time to prevent factitious CFD variations (20). In addition, the present study showed an increase or decrease in CFD levels with an irregular tendency over a storage period of $6 \mathrm{~h}$. This result was presumed to be due to the influence of cell lysis or changes in DNase activity/levels over time. Deregulation of caspases occurs during cancer development and progression, releasing DNA or nucleosome into the circulated blood (21), which can increase CFD in patients with cancer. Conversely, DNA is rapidly degraded and hydrolyzed from the blood circulation by DNases, and the half-life of CFD in blood seems to be short (22), which can cause reductions in the levels of CFD. Stability of CFD derived from cancer cells is more fragile than that of DNA from healthy cells, and CFD from cancer cells is more fragile than that of healthy 


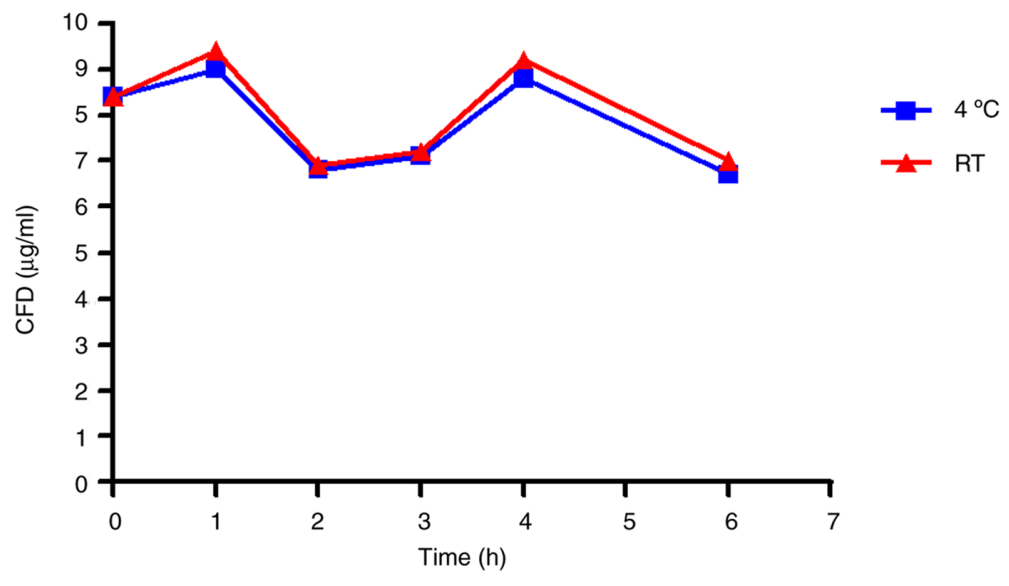

\begin{tabular}{|c|c|c|c|c|c|c|c|c|c|c|}
\hline & Time (h) & Baseline & $1 \mathrm{~h}$ & $2 \mathrm{~h}$ & $3 \mathrm{~h}$ & $4 \mathrm{~h}$ & $6 \mathrm{~h}$ & Sources & $\mathrm{F}$ & P-value \\
\hline \multirow{3}{*}{$\begin{array}{c}\text { Mean } \pm \text { SD } \\
(\mu \mathrm{g} / \mathrm{ml})\end{array}$} & $4^{\circ} \mathrm{C}$ group & & $9.4 \pm 0.5$ & $6.9 \pm 0.3$ & $7.2 \pm 0.3$ & $9.2 \pm 0.5$ & $7.0 \pm 0.3$ & Time & 481.038 & $<0.001$ \\
\hline & & $8.4 \pm 0.2$ & & & & & & Group & 1.004 & 0.346 \\
\hline & RT group & & $9.0 \pm 0.2$ & $6.8 \pm 0.5$ & $7.1 \pm 0.3$ & $8.8 \pm 0.5$ & $6.7 \pm 0.5$ & $\begin{array}{l}\text { Time } x \\
\text { Group }\end{array}$ & 2.375 & 0.090 \\
\hline \multirow{3}{*}{$\begin{array}{l}\text { RSD } \\
(\%)\end{array}$} & $4^{\circ} \mathrm{C}$ group & & 4.8 & 4.5 & 4.7 & 5.1 & 4.0 & - & - & - \\
\hline & & 4.0 & & & & & & & & \\
\hline & RT group & & 2.7 & 4.6 & 3.7 & 5.3 & 7.5 & - & - & - \\
\hline
\end{tabular}

Figure 2. Fluorescence-based CFD according to varying storage condition. At both $\mathrm{RT}$ and $4^{\circ} \mathrm{C}$, the $\mathrm{CFD}$ values increased after $1 \mathrm{~h}$, decreased at $2 \mathrm{~h}$, increased after $3 \mathrm{~h}$ and then decreased after $6 \mathrm{~h}$. The changes in CFD values were significant according to time course. $\mathrm{F}=481.038$, $\mathrm{P}<0.001$. The changes were not consistent over time. RSD, relative standard deviation; CFD, cell free DNA; RT, room temperature.

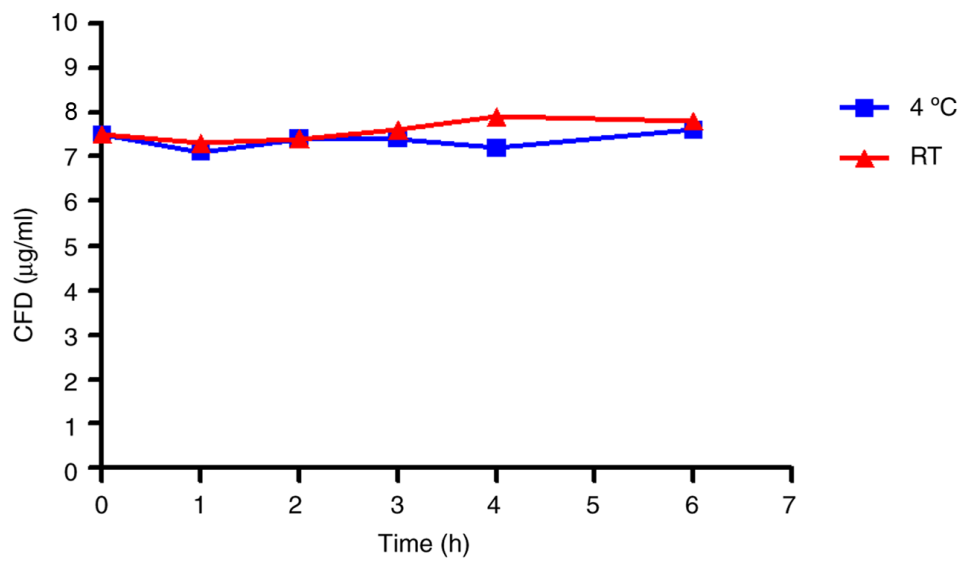

\begin{tabular}{|c|c|c|c|c|c|c|c|c|c|c|}
\hline & Time $(\mathrm{h})$ & Baseline & $1 \mathrm{~h}$ & $2 \mathrm{~h}$ & $3 \mathrm{~h}$ & $4 \mathrm{~h}$ & $6 \mathrm{~h}$ & Sources & $\mathrm{F}$ & $\mathrm{P}$-value \\
\hline \multirow{3}{*}{$\begin{array}{c}\text { Mean } \pm \text { SD } \\
(\mu \mathrm{g} / \mathrm{ml})\end{array}$} & $4^{\circ} \mathrm{C}$ group & & $7.1 \pm 0.5$ & $7.4 \pm 0.2$ & $7.4 \pm 0.2$ & $7.2 \pm 0.1$ & $7.6 \pm 0.4$ & Time & 3.387 & 0.007 \\
\hline & & $7.5 \pm 0.1$ & & & & & & Group & 1.342 & 0.280 \\
\hline & RT group & & $7.3 \pm 0.2$ & $7.4 \pm 0.3$ & $7.6 \pm 0.4$ & $7.9 \pm 0.1$ & $7.8 \pm 0.2$ & Time $x$ Group & 1.643 & 0.156 \\
\hline \multirow{3}{*}{$\begin{array}{l}\text { RSD } \\
(\%)\end{array}$} & $4^{\circ} \mathrm{C}$ group & & 6.1 & 3.5 & 4.3 & 6.4 & 5.0 & - & - & - \\
\hline & & 9.4 & & & & & & & & \\
\hline & RT group & & 4.3 & 5.5 & 4.3 & 3.4 & 2.4 & - & - & - \\
\hline
\end{tabular}

Figure 3. Influence of freeze-thawing in the fluorescence-based CFD assay. Plasma samples were stored frozen as aliquots at $-80^{\circ} \mathrm{C}$ and thawed after 1 month to assess the influence of freezing, and the reproducibility of the results. There was a significant difference in CFD values after freeze-thawing according to storage time. $\mathrm{F}=3.387, \mathrm{P}=0.007$. However, there was no significant difference in $\mathrm{CFD}$ values after freeze-thawing based on the previously exposed temperature. $\mathrm{F}=1.342, \mathrm{P}=0.280$. RSD, relative standard deviation; $\mathrm{CFD}$, cell free DNA; RT, room temperature. 
donors, and is thus easily disrupted (23). Therefore, when fluorescence-based CFD assays are applied to patients with cancer, the pre-analytical period identified in the present study must be strictly controlled.

The fluorescence-based CFD assay is only a quantitative method for assaying CFD, and cannot be applied for individual genomic profile analysis. In addition, the quantitative method does not provide a measure of tumor-specific CFD, but instead both germline and tumor CFD $(17,18)$. Due to these limitations, it cannot be applied to precision medicine using tumor mutation profiling of tumor-specific CFD, such as the Mass-array ${ }^{\circledR}$ system (14). However, tumor-specific CFD assays are well known for their correlation with tumor volume. Abbosh et al (24) reported that a tumor volume of $10 \mathrm{~cm}^{3}$ was required for detection sensitivity of tumor-specific CFD tests, which is considerably larger than the volume of an early stage/asymptomatic tumor (24). Whilst, considering that CFD primarily emerges from tissue in the surrounding environment during cancer development rather than from cancer cells themselves, simple quantitative fluorescence-based CFD may be more useful for roles such as response monitoring, prognostication and early detection. In particular, considering that the cure rate is increasing in the minimal disease status before definitive clinical disease in the era of immunotherapy (25), fluorescence-based CFD quantitative assays may be used to detect early disease, such as minimal residual disease in post-operative settings or for long-term surveillance.

The present study evaluated only the basic performance of the fluorescence-based CFD assay and did not specify any usage scenarios (for example, detection of cancer or response to treatments). Although there are several limitations, the present study laid the foundation for ongoing research into fluorescence-based CFD assays. Additional studies are required to allow the $\mathrm{CFD}$ assay to provide a more robust, consistent and informative method for use in clinical settings. It is necessary to reconfirm the results of the present study using a larger cohort of patients with cancer, and conduct future studies to demonstrate clinical relevance, such as a cohort study for cancer detection, evaluating cancer treatment response and detecting recurrence for surveillance.

In conclusion, the fluorescence-based CFD assay proved to be simple and accurate, but was limited due to variations in the pre-analytical storage period. The present study showed that CFD measurements using processed plasma within $1 \mathrm{~h}$ is optimal. The effects of substantial changes according to storage conditions were reduced after freeze-thawing, thus, studies using stored samples, such as those from a biobank are viable.

\section{Acknowledgements}

Not applicable.

\section{Funding}

The present study was supported by the Research Institute for Convergence of Biomedical Science and Technology from the Pusan National University Yangsan Hospital (grant no. 30-2019-015).

\section{Availability of data and materials}

The datasets used and/or analyzed during the present study are available from the corresponding author on reasonable request.

\section{Authors' contributions}

JJK analyzed and interpreted the data, and drafted and revised the manuscript. KP designed the current study, performed the experiments, analyzed and interpreted the data, and drafted and revised the manuscript. YRH, and SHK performed the experiments. SBO, SYO, YJH analyzed and interpreted the data, and drafted the manuscript. MSY assisted with the statistical analysis. JJK and KP confirm the authenticity of all the raw data. All authors have read and approved the final manuscript.

\section{Ethics approval and consent to participate}

The research protocol used in the present study was approved by the Institutional Review Board of Pusan National University Yangsan Hospital (Yangsan, Republic of Korea; approval no. 04-2019-024), and written informed consent was obtained from all participants.

\section{Patient consent for publication}

Not applicable.

\section{Competing interests}

The authors declare that they have no competing interests.

\section{References}

1. Stroun M, Maurice P, Vasioukhin V, Lyautey J,Lederrey C, Lefort F, Rossier A, Chen XQ and Anker P: The origin and mechanism of circulating DNA. Ann NY Acad Sci 906: 161-168, 2000.

2. Schwarzenbach H, Hoon DS and Pantel K: Cell-free nucleic acids as biomarkers in cancer patients. Nat Rev Cancer 11: 426-437, 2011.

3. Gormally E, Caboux E, Vineis P and Hainaut P: Circulating free DNA in plasma or serum as biomarker of carcinogenesis: Practical aspects and biological significance. Mutat Res 635: 105-117, 2007.

4. Agassi R, Czeiger D, Shaked G, Avriel A, Sheynin J,Lavrenkov K, Ariad S and Douvdevani A: Measurement of circulating cell-free DNA levels by a simple fluorescent test in patients with breast cancer. Am J Clin Pathol 143: 18-24, 2015.

5. Boddy JL, Gal S, Malone PR, Harris AL and Wainscoat JS: Prospective study of quantitation of plasma DNA levels in the diagnosis of malignant versus benign prostate disease. Clin Cancer Res 11: 1394-1399, 2005.

6. Kamat AA, Baldwin M, Urbauer D, Dang D, Han LY, Godwin A, Karlan BY, Simpson JL, Gershenson DM, Coleman RL, et al: Plasma cell-free DNA in ovarian cancer: An independent prognostic biomarker. Cancer 116: 1918-1925, 2010.

7. Jahr S, Hentze H, Englisch S, Hardt D, Fackelmayer FO, Hesch RD and Knippers R: DNA fragments in the blood plasma of cancer patients: Quantitations and evidence for their origin from apoptotic and necrotic cells. Cancer Res 61: 1659-1665, 2001.

8. Ziegler A, Zangemeister-Wittke U and Stahel RA: Circulating DNA: A new diagnostic gold mine? Cancer Treat Rev 28: 255-271, 2002.

9. Ryan BM, Lefort F, McManus R, Daly J, Keeling PW, Weir DG and Kelleher D: A prospective study of circulating mutant KRAS2 in the serum of patients with colorectal neoplasia: Strong prognostic indicator in postoperative follow up. Gut 52: 101-108, 2003. 
10. Anker P, Mulcahy H, Chen XQ and Stroun M: Detection of circulating tumour DNA in the blood (plasma/serum) of cancer patients. Cancer Metastasis Rev 18: 65-73, 1999.

11. Devonshire AS, Whale AS, Gutteridge A, Jones G, Cowen S, Foy CA and Huggett JF: Towards standardisation of cell-free DNA measurement in plasma: Controls for extraction efficiency, fragment size bias and quantification. Anal Bioanal Chem 406: 6499-6512, 2014.

12. Alcaide M, Cheung M, Hillman J, Rassekh SR, Deyell RJ, Batist G, Karsan A, Wyatt AW, Johnson N, Scott DW, et al Evaluating the quantity, quality and size distribution of cell-free DNA by multiplex droplet digital PCR. Sci Rep 10: 12564, 2020.

13. Janku F, Huang HJ, Fujii T, Shelton DN, Madwani K, Fu S, Tsimberidou AM, Piha-Paul SA, Wheler JJ, Zinner RG, et al: Multiplex KRASG12/G13 mutation testing of unamplified cell-free DNA from the plasma of patients with advanced cancers using droplet digital polymerase chain reaction. Ann Oncol 28: 642-650, 2017.

14. Kulasinghe A, Monkman J, Nalder M, Leary CO, Ladwa R and Bayre KO: Transformation or progression from adenocarcinoma to small cell lung cancer detected by serially tracking mutations in the blood. Reports 3: 33, 2020.

15. Roth C, Pantel K, Müller V, Rack B, Kasimir-Bauer S, Janni W and Schwarzenbach H: Apoptosis-related deregulation of proteolytic activities and high serum levels of circulating nucleosomes and DNA in blood correlate with breast cancer progression. BMC Cancer 11: 4, 2011.

16. Fiala $\mathrm{C}$ and Diamandis EP: Utility of circulating tumor DNA in cancer diagnostics with emphasis on early detection. BMC Med 16: 166, 2018.

17. Goldshtein H, Hausmann MJ and Douvdevani A: A rapid direct fluorescent assay for cell-free DNA quantification in biological fluids. Ann Clin Biochem 46: 488-494, 2009.

18. Chiminqgi M, Moutereau S, Pernet P, Conti M, Barbu V, Lemant J, Sacko M, Vaubourdolle M and Loric S: Specific real-time PCR vs. fluorescent dyes for serum free DNA quantification. Clin Chem Lab Med 45: 993-995, 2007.
19. Park K, Woo M, Kim JE, Ahn JH, Jung KH, Roh J, Gong G and Kim SB: Efficacy of assessing circulating cell-free DNA using a simple fluorescence assay in patients with triple-negative breast cancer receiving neoadjuvant chemotherapy: A prospective observational study. Oncotarget 9: 3875-3886, 2017.

20. Yu SC, Lee SW, Jiang P, Leung TY, Chan KC, Chiu RW and Lo YM: High-resolution profiling of fetal DNA clearance from maternal plasma by massively parallel sequencing. Clin Chem 59: 1228-1237, 2013.

21. López-Otín C and Matrisian LM: Emerging roles of proteases in tumour suppression. Nat Rev Cancer 7: 800-808, 2007.

22. Rumore P, Muralidhar B, Lin M, Lai C and Steinman CR: Haemodialysis as a model for studying endogenous plasma DNA: Oligonucleosome-like structure and clearance. Clin Exp Immunol 90: 56-62, 1992.

23. Stroun M, Anker P, Maurice P, Lyautey J, Lederrey C and Beljanski M: Neoplastic characteristics of the DNA found in the plasma of cancer patients. Oncology 46: 318-322, 1989.

24. Abbosh C, Birkbak NJ, Wilson GA, Jamal-Hanjani M, Constantin T, Salari R, Le Quesne J, Moore DA, Veeriah S, Rosenthal R, et al; TRACERx consortium; PEACE consortium: Phylogenetic ctDNA analysis depicts early-stage lung cancer evolution. Nature 545: 446-451, 2017.

25. Vansteenkiste J, Wauters E, Reymen B, Ackermann CJ, Peters S and De Ruysscher D: Current status of immune checkpoint inhibition in early-stage NSCLC. Ann Oncol 30: 1244-1253, 2019.

This work is licensed under a Creative Commons Attribution-NonCommercial-NoDerivatives 4.0 International (CC BY-NC-ND 4.0) License. 